\title{
Physical and Chemical Factors of Breeding Sites Affecting Susceptibility and Biochemical Activity of Mosquito, Culex pipiens (Diptera: Culicidae) to Some Insecticides
}

\author{
Abdelbaset B. Zayed ${ }^{1}$, Walaa A. Moselhy ${ }^{1}$, Azza A. Mostafa ${ }^{2}$, Hanaa I. Mahmoud ${ }^{1}$, \\ Shaimaa H. Hassan ${ }^{1}$ \\ ${ }^{1}$ Zoology Department, Faculty of Science, Al-Azhar University (Girls Branch), Cairo, Egypt \\ ${ }^{2}$ Pesticides Department, Research Institute of Medical Entomology, Ministry of Health \& Populations, Giza, Egypt
}

Email address:

abzayed@gmail.com (A. B. Zayed)

${ }^{*}$ Corresponding author

\section{To cite this article:}

Abdelbaset B. Zayed, Walaa A. Moselhy, Azza A. Mostafa, Hanaa I. Mahmoud, Shaimaa H. Hassan. Physical and Chemical Factors of Breeding Sites Affecting Susceptibility and Biochemical Activity of Mosquito, Culex pipiens (Diptera: Culicidae) to Some Insecticides. International Journal of Ecotoxicology and Ecobiology. Vol. 4, No. 2, 2019, pp. 51-57. doi: 10.11648/j.ijee.20190402.12

Received: March 23, 2019; Accepted: May 6, 2019; Published: June 4, 2019

\begin{abstract}
Culex pipiens is the common mosquito in Egypt and worldwide species. There is limited evidence on the effects of breeding place nature on the susceptibility of $C x$. pipiens to different insecticides. This study aims to evaluate the effects of some physiochemical parameters of different breeding sites in Egypt on $C x$. pipiens susceptibility to some recommended insecticides. Mosquito larvae were collected from fresh and sewage water from the selected sites at different areas in Egypt. Water was analyzed in the laboratory to determine salinity and $\mathrm{pH}$. Bioassays and biochemical assays were carried out to determine susceptibility of both larvae and adult under different physiochemical parameters. Larvae and adult that were collected from sewage water with high salinity and acidic medium showed higher resistant to all tested insecticides than those of fresh water with low salinity. The present study provided information of the susceptibility of $C x$. pipiens mosquito larvae and adult to some insecticides commonly used under different environmental changes.
\end{abstract}

Keywords: Culex pipiens, Insecticide Resistance Assays, Breeding Places, Salinity, pH

\section{Introduction}

In Egypt, the mosquito Culex pipiens is the principal mosquito vector of filariasis and some arboviruses such as West Nile Virus and Rift Valley Fever virus [1, 2]. $C x$. pipiens, therefore, is the main target in control programs against these diseases.

Culex pipiens larvae invest all kinds of aquatic habitats for breeding, in which, their physiochemical parameters are important factors for survival and development of mosquitoes. The breeding sites of mosquitoes are sometimes contaminated with pollutants from various sources such as sewage from industrial and agricultural fields [3, 4].

Physiochemical parameters such as temperature, salinity, and $\mathrm{pH}$ have a significant influence on the occurrence and larval abundance among mosquito species [5]. Also, these characteristics may have some effects on mosquito vectors susceptibility to traditional used insecticides. Understanding of breeding behavioral pattern among mosquito populations is one of the key elements for reaching the goal of mosquito control.

There is limited evidence on the effects of breeding site nature on the susceptibility of mosquitoes. In this study, the effect of physiochemical parameters at different breeding sites on susceptibility of $C x$. pipiens to different insecticides was studied. The larvae were collected from different breeding places in selected localities represent different Egyptian governorates (Aswan, Kafr El Sheikh and Suez). 


\section{Materials and Methods}

\subsection{Study Area}

Culex pipiens larvae were collected from Aswan, (Upper Egypt), Kafr El Sheikh, (Nile Delta) and Suez governorates. From each governorate larvae were collected from both sewage and fresh water. Breeding site water samples were collected to measure the following physiochemical parameters; the salinity, $\mathrm{pH}$ as well as temperature. Measurement of these parameters was carried out using water test (Hanna instrument H1991301).

\subsection{Collection of Culex pipiens Larvae}

As soon as the localities were determined and during regular mosquito surveillance sampling, sufficient dips with a $7 \mathrm{~cm}$ diameter metal ring, to which mouslin net was fixed, with about 1.3 meters long wooden handle. Collection of $C x$. pipiens larvae was conducted by dropping the net gently and smoothly under the water surface of the selected area. Representative sample of the population was transferred to $20 \mathrm{~cm}$ diameter enamel plates, then were exposed to sun light. The larvae were transferred to the laboratory in jars that filled with the water from their habitat. The larvae were identified morphologically to the species level [6].

Sufficient numbers of larvae were used for larval bioassay and biochemical assays. Other larvae were reared in laboratory until emergence of adult. They were hold in the insectary in which temperature was maintained at $25 \pm 3 \mathrm{C}^{\circ}$ and humidity between $70-80 \%$. The emerging adults were fed on $10 \%$ sucrose solution until four days then used for adult bioassay in addition to biochemical assays [7].

\subsection{Toxicological Studies}

\subsubsection{Larval Bioassay}

In this study, three organophosphorus insecticides; temephos, chloropyrifos and primiphos methyl recommended for mosquito larval control by the World Health Organization's Pesticide Evaluation Scheme (WHOPES) for evaluation of mosquito larvae resistance were used [8].

Single-concentration diagnostic tests were conducted to monitor insecticide resistance [9]. The diagnostic concentrations for tested insecticides were; $0.02 \mathrm{ppm}$ temephos, and $0.01 \mathrm{ppm}$ chloropyrifos, while the diagnostic concentration of primiphos methyl was calculated by measuring $\mathrm{LC}_{99}$ of susceptible population and then duplicated $(0.1 \mathrm{ppm})$.

The bioassay was conducted according to WHO standard procedure [10] with four replicates for each test. Twenty five Larvae per replicates were added in beaker contained $249 \mathrm{ml}$ tap water and $1 \mathrm{ml}$ of the insecticide concentration was infiltrated under the water surface with a pipette. Other four replicates were treated with $1 \mathrm{ml}$ ethanol as control.

\subsubsection{Adult Bioassay}

Three pyrethroid insecticides (Lambda- cyhalothrin, Deltamethrin and Permethrin) commonly recommended for mosquito adults control were tested against the six studied $C x$. pipiens populations. The proposed diagnostic concentration by WHO $[9,11]$ for each insecticide was used to monitor insecticide resistance $(0.05 \%$ Lambdacyhalothrin, $0.05 \%$ Deltamethrin and $0.75 \%$ Permethrin).

The adult bioassays were performed using WHO test kits and method for measuring insecticide susceptibility [11]. Each experiment consisted of three replicates with twenty females in each. Non-blood fed, 3 to 5 days old females were exposed to insecticide-treated filter papers. The mosquitoes were exposed to the insecticide for an hour with the assay cylinders in a vertical position. After the exposure, mosquitoes were transferred into the holding tubes with untreated papers and allowed a 24 hour recovery period after which mortality was recorded. A group of 20 mosquitoes were exposed to papers treated only with the used solvents (ethanol) for an hour as control. The bioassay was carried out at $25 \pm 2{ }^{\circ} \mathrm{C}$ and the mosquitoes were supplied with a $10 \%$ sugar solution meal during the recovery period.

\subsection{Biochemical Assay}

\subsubsection{Preparation of Mosquito Extracts}

For total protein, acetylcholinesterase and glutathione-Stransferase assays, $50 \mathrm{mg}$ samples of mosquitoes were mechanically homogenized in $1 \mathrm{ml}$ distilled water by a chilled glass telfon homogenizer. Homogenates were centrifuged at 8000 r.p.m. for $15 \mathrm{~min}$ at $5^{\circ} \mathrm{C}$ in a cooling centrifuge and the supernatant were kept in a deep freezer till used [12].

\subsubsection{Determination of Total Protein Activity}

Protein concentrations were determined by incubating 10 $\mu \mathrm{L}$ of larval homogenate with $290 \mu \mathrm{L}$ of Bio-Rad protein assay solution for $10 \mathrm{~min}$. Absorption was then measured at $570 \mathrm{~nm}$ and bovine serum albumin was used as the standard using double beam ultraviolet / visible spectrophotometer (spectronic 1201, Milton Roy Co., USA) [13].

\subsubsection{Determination of Acetylcholinesterase Activity}

Acetylcholinesterase (AChE) activity was measured using acetylcholine bromide $(\mathrm{AChBr})$ as substrate; the resulted colour was measured colorimetrically at $515 \mathrm{~nm}$ [14].

\subsubsection{Determination of Glutathione-S-transferase Activity}

The activity of GST was evaluated using three-ml reaction mixture contained $(0.05 \mathrm{ml}$ of $50 \mathrm{mM}$ CDNB [1-chloro-2, 4dinitrobenzene], $0.15 \mathrm{ml}$ of reduced glutathione (GSH) were added to $2.79 \mathrm{ml}$ of $40 \mathrm{mM}$ buffer saline ( $\mathrm{pH} \mathrm{6.8)}$ ) and 0.01 $\mathrm{ml}$ enzyme source) was added. The mixture was incubated for 2-3 $\mathrm{min}$ at $20^{\circ} \mathrm{C}$. The increasing in absorbance value (OD) was recorded for $5 \mathrm{~min}$, and the GST activity ( $\mu \mathrm{M} \mathrm{mg}$ protein ${ }^{-1} \min ^{-1}$ ) was then calculated [15].

\subsection{Data Analysis}

One-way analysis of variance (ANOVA) was used to compare insecticide resistance profiles in different breeding sites. All levels of statistical significance were determined at $P<0.05$. Statistical analyses were carried out using SPSS version 20 (2012) [16] for Windows (SPSS Inc, USA). Biochemical assay results were calculated and plotted using Microsoft Excel (Microsoft Corporation, 2010). 


\section{Result}

\subsection{Insecticide Susceptibility of Culex. pipiens Populations}

In figure 1; the susceptibility of the $C x$. pipiens larvae to the three tested insecticides is plotted against the different measured characteristics of breeding water (salinity, $\mathrm{pH}$ and temperature). On other hand, figure 2 showed the effect of these parameters on the susceptibility of the emerged adults to the test adulticides.

Data in figures (1 and 2) showed that, sewage water with high salinity and acidic medium ranging from (2.5-3) and (66.4), respectively decreased susceptibility of $C x$. pipiens larvae to all tested insecticides, while fresh water with law salinity and alkaline medium ranging from $(0.3-0.64)$ and (7.6- 8.6), respectively resulted more sensitive mosquito larvae to all tested insecticides.

Also, results showed that $C x$. pipiens mosquito larvae collected from Kafr El Sheikh were more resistant to all tested insecticides followed by Suez ones, while Aswan mosquito larvae were the most susceptible population examined. On other hand, temephos was the most effective larvicides, while lambda- cyhalothrin was the most effective adulticides.

The collected larvae from sewage water in Kafr El Sheikh showed significant decrease in susceptibility $(\mathrm{p}<0.05)$ to all larvicides with mortality rates $(40,60$ and $85 \%$ to chloropyrifos, primiphos methyl and temephos, respectively) if compared with those of fresh water larvae (60, 90 and 100\% mortality for chloropyrifos, primiphos methyl and temephos, respectively) (Figure 1). Also there was significantly decrease in susceptibility of emerged adult $(\mathrm{p}<0.05)$ from sewage water with mortality rates $(67,70$ and $75 \%$ to permethrin, deltamethrin and lambda- cyhalothrin, respectively), while the fresh water larvae reduced mortality rates in emerged adults (73, 78 and $82 \%$ to permethrin, deltamethrin and lambdacyhalothrin, respectively) (Figure 2).

Larvae that were collected from sewage water in Suez, showed significant decrease in susceptibility $(\mathrm{p}<0.05)$ after exposure to primiphos methyl and chloropyrifos as larvicides $(82,45 \%$, respectively) if compared with percent mortality $(100,70 \%$, respectively) in fresh water. The emerged adults had the same manner against permethrin as adulticide $(72 \%)$ if compared with the effect of characteristics of the fresh water $(80 \%)$. However, there was no significantly difference in susceptibility $(\mathrm{p}>0.05)$ between sewage water and fresh water after exposure to temephos as larvicide (90, 80\%, respectively). As well as deltamethrin (75 and 84\%, respectively) and lambda- cyhalothrin $(81,87.5$, respectively) used as adulticides (Figures 1,2).

In Aswan, there were no significantly differences in insecticide susceptibility of sewage mosquitoes and fresh water ones $(p>0.05)$, except in the treatment with chloropyrifos and primiphos methyl as larvicides as well as permethrin as adulticides $(\mathrm{p}<0.05)$.

Culex pipiens population collected from both sewage and fresh breeding sites showed high mortality percent (100\%) after exposure to temephos, while primiphos methyl showed mortality percent $(87,100 \%)$ in sewage water population and fresh water one, respectively. Chloropyrifos recorded decrease in susceptibility of sewage water population with mortality $61 \%$, while, fresh water with mortality $94 \%$ (Figure 1).

As adulticides permethrin showing some degree of resistant in sewage water population $76 \%$, while, $87 \%$ mortality indicated in fresh water one. Deltamethrin recorded mortality percent $83 \%$ in sewage water and $87 \%$ in fresh water populations. Lambda- cyhalothrin was most effective insecticides with mortality percent $84 \%$ in sewage water and $90 \%$ in fresh water populations (Figure 2).

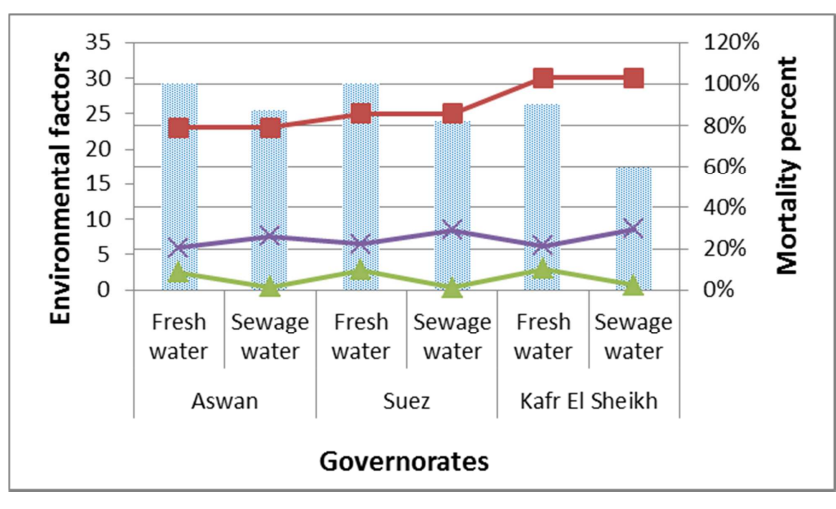

Primiphos methyl

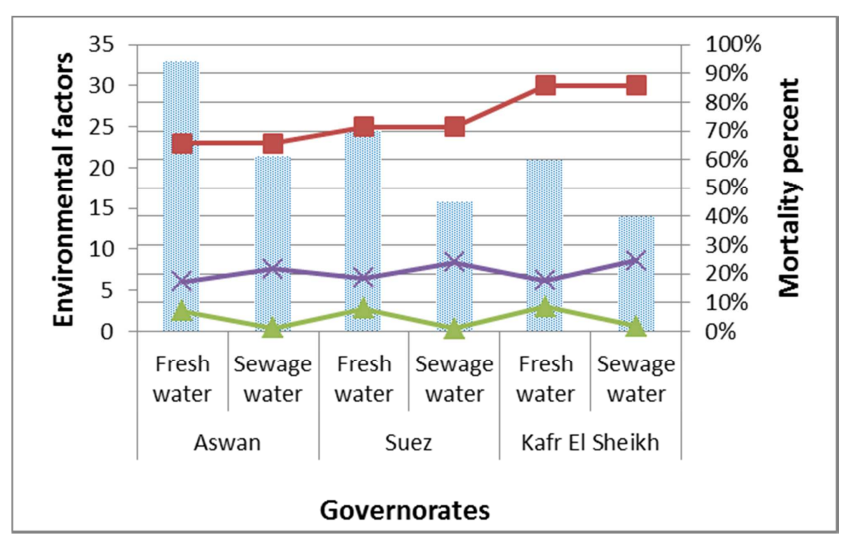

Chloropyrifos

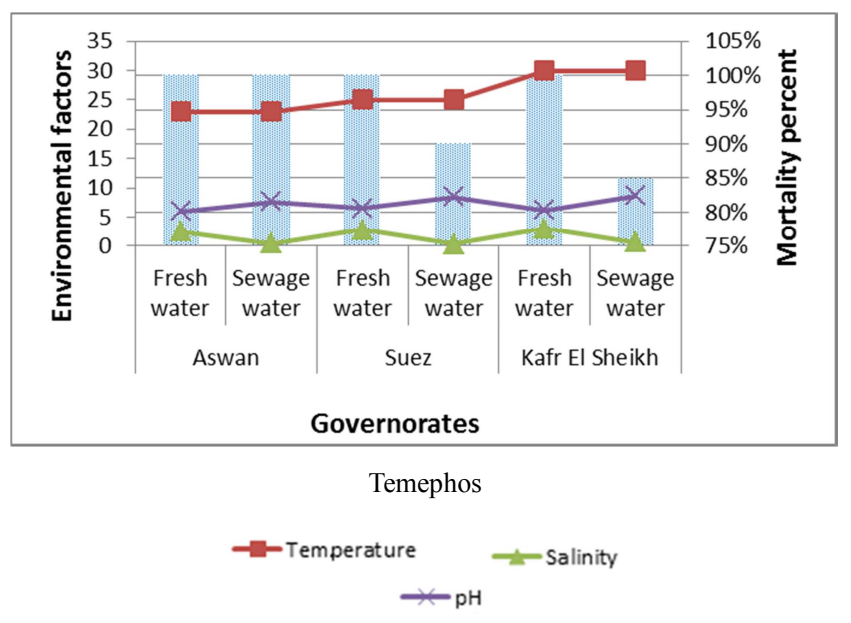

Figure 1. Physiochemical parameters of breeding water and their effect on susceptibility of Culex pipiens larvae to different insecticides. 


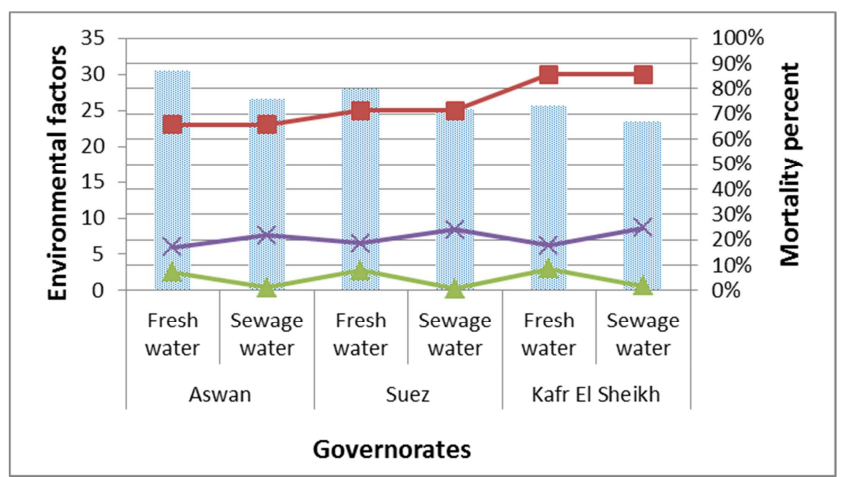

Permethrin

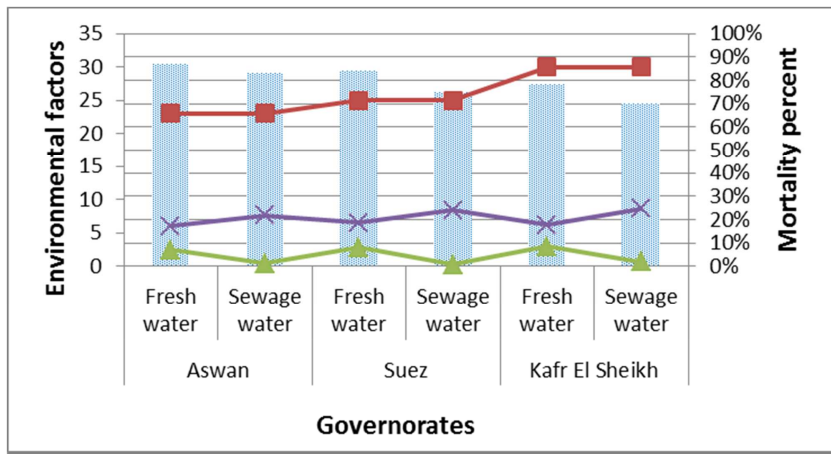

Deltamethrin

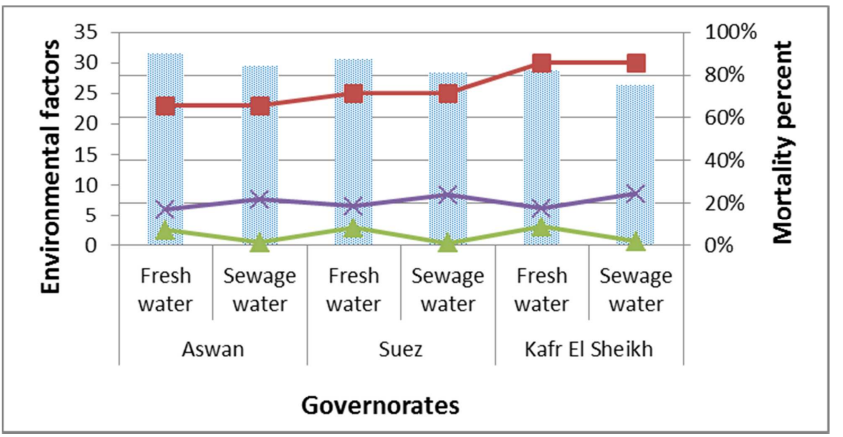

Lambda- cyhalothrin

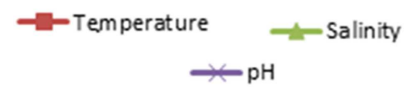

Figure 2. Physiochemical parameters of breeding water and their effect on susceptibility of emerged Culex pipiens adults to different insecticides.

\subsection{Biochemical Assay}

In order to explain the response of $C x$. pipiens that brought from different breeding at different localities the biochemical assay was carried out.

After measurement of the total protein in all tested mosquitoes, the values were used to calibrate the activity of acetylcholinesterase and glutathione- S- transferase enzymes.

From figures 3, 4, 5 and 6, AChE and GST activities exhibited higher levels in sewage mosquitoes than fresh water ones.

In Kafr El- Sheikh originated populations AChE level recorded elevation in both larvae and adult from sewage population (3.3 and $7.9 \mu \mathrm{g} \quad \mathrm{AChBr} / \mathrm{min} / \mathrm{mg}$ protein, respectively). On other hand, the activity of AChE decreased in both larvae and adult collected from fresh water (2.04 and 6.2 for $\mathrm{AChE} \mu \mathrm{g} \mathrm{AChBr} / \mathrm{min} / \mathrm{mg}$ protein, respectively). In the same manner GST showed elevation in both larvae and adult (2111 and $2813 \mathrm{n}$ mole sub conjugated $/ \mathrm{min} / \mathrm{mg}$ protein, respectively), and decreased in both larvae and adult collected from fresh water bodies (2079 and $1409 \mathrm{n}$ mole sub conjugated $/ \mathrm{min} / \mathrm{mg}$ protein, respectively).

In Suez populations, AChE level recorded elevation in both larvae and adult collected from sewage population (2.6 and $6 \mu \mathrm{g} \mathrm{AChBr} / \mathrm{min} / \mathrm{mg}$ protein for $\mathrm{AChE}$, respectively). On other hand, the activity of AChE decreased in both larvae and adult collected from fresh water (1.3 and $4.2 \mu \mathrm{g}$ $\mathrm{AChBr} / \mathrm{min} / \mathrm{mg}$ protein, respectively). In the same manner GST showed elevation in both larvae and adult (3922 and $2303 \mathrm{n} \mathrm{mole} \mathrm{sub} \mathrm{conjugated} / \mathrm{min} / \mathrm{mg}$ protein, respectively) and (2010 and $1013 \mathrm{n}$ mole sub conjugated $/ \mathrm{min} / \mathrm{mg}$ protein for GST, respectively).

In Aswan, populations $\mathrm{AChE}$ level recorded elevation in both larvae and adult collected from sewage population (2.2 and $5.43 \mu \mathrm{g} \mathrm{AChBr} / \mathrm{min} / \mathrm{mg}$ protein, respectively). On other hand, the activity of AChE decreased in both larvae and adult collected from fresh water bodies (1.5 and $3.8 \mu \mathrm{g}$ $\mathrm{AChBr} / \mathrm{min} / \mathrm{mg}$ protein, respectively). In the same manner GST showed elevation both larvae and adult (1107 and $1627 \mathrm{n}$ mole sub conjugated $/ \mathrm{min} / \mathrm{mg}$ protein, respectively) and (895 and $998 \mathrm{n}$ mole sub conjugated/min/mg protein, respectively).

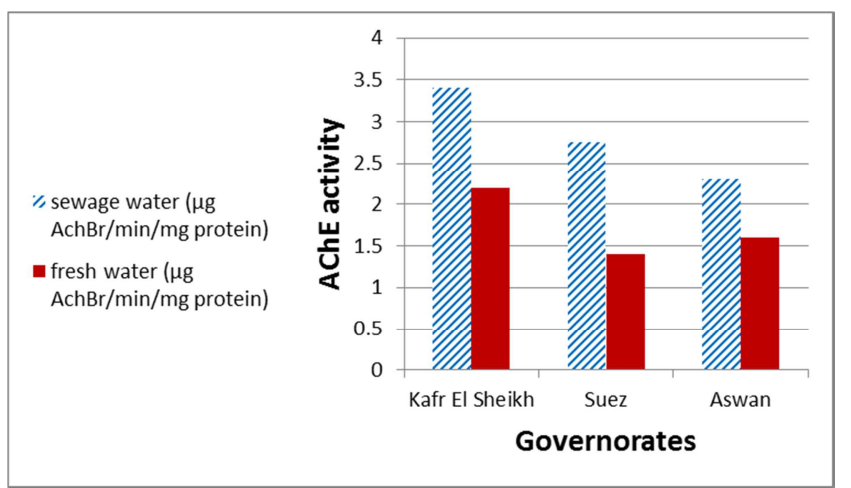

Figure 3. Effect of breeding site nature on Acetylcholinesterase level in Culex pipiens larvae.

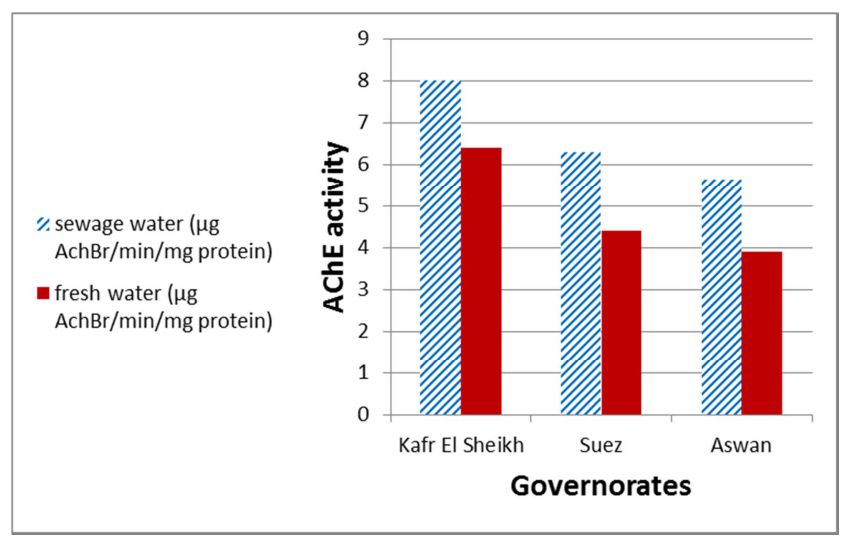

Figure 4. Effect of breeding site nature on Acetylcholinesterase level in Culex pipiens emerging adult. 


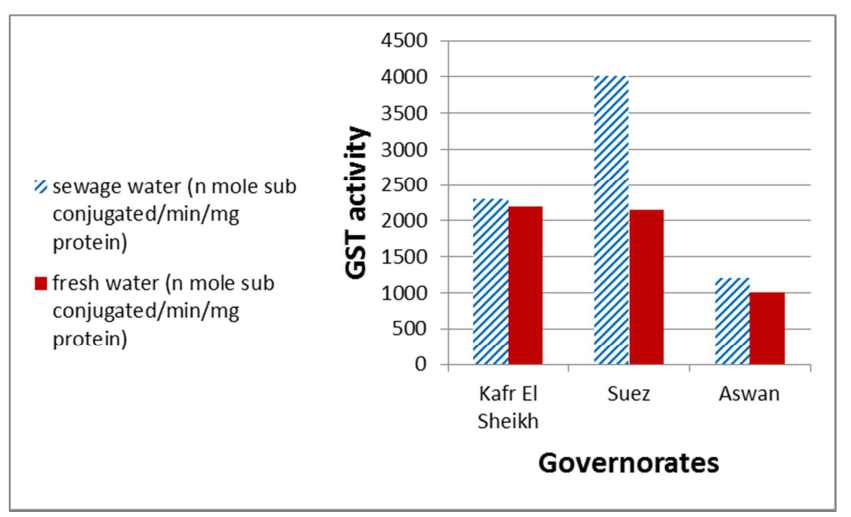

Figure 5. Effect of breeding site nature on Glutathione-S-transferase level in Culex pipiens larvae.

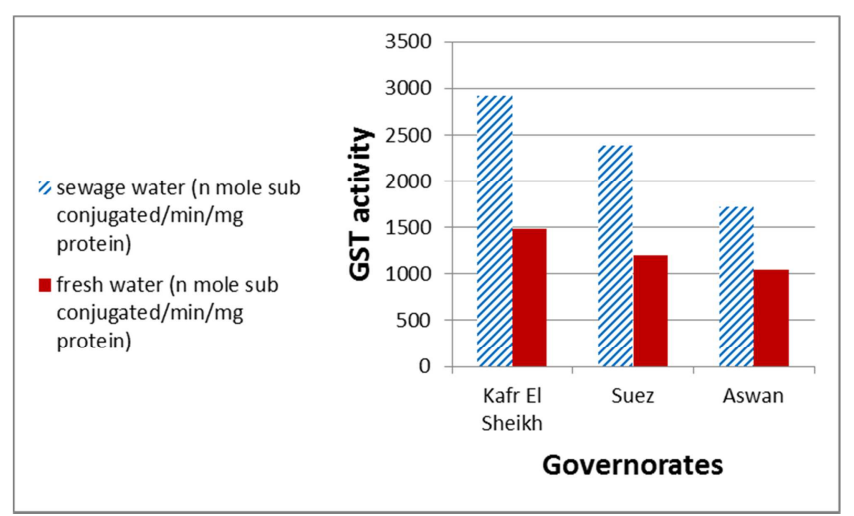

Figure 6. Effect of breeding site nature on Glutathione-S-transferase level in Culex pipiens emerging adult.

\section{Discussion}

The mosquito control continues to be an important strategy in controlling and preventing the mosquito-borne diseases. The primary approach used for mosquito control is mainly relied on pesticides. However, very few pesticide types are currently registered for mosquito control. Furthermore, many mosquito species have developed resistance to various classes of pesticides [8, 17]. Insecticide resistance has been known to be prevalent in several insect species including mosquitoes. It has become a major problem in vector control programme due to pesticide resistance through detoxification enzymes. Current environmental trends including climate change, increased exchanges and urbanization, affect the distribution of disease vectors and subsequently the transmission and incidence of human pathogens [18].

The rapid change in environment and rise developing industrial waste increase the pollution on mosquito breeding places and affect the chemical use in control mosquitoes.

The present study provided information of the susceptibility of $C x$. pipiens mosquito larvae and adult to some insecticides commonly used under different environmental changes. The study investigated the effect of physiochemical characteristics changing due to variation of the breeding places; sewage and fresh water on the insecticide susceptibility of three mosquito populations from different three Egyptian governorates; Kafr El Sheikh, Suez and Aswan. Physiochemical parameters (salinity, $\mathrm{pH}$ and temperature) appeared to significantly influence the larval insecticide susceptibility as well as subsequent emerging adult. The study revealed an evidence of the effect of the nature of breeding sites on susceptibility of mosquito.

The present study indicated that, susceptibility of swage $C x$. pipiens larvae and adult populations was significantly lower (high salinity and low $\mathrm{pH}$ value) than fresh water populations in all three tested governorates.

Physiochemical feature in mosquito breeding sites has some influence on mosquito vector oviposition, survival and spatial distribution [19]. The size of the adults of Aedes mosquito emerged from sewage drains was bigger than those emerged from rest of the larval habitats [20]. These variations may be due to that the resource content of the sewage drains was higher than other habitats, which contributed to the development of large mosquitoes with higher nutrient reserves [21, 22].

In general, the present study revealed that, temephos was the most effective larvicide against all populations collected from different environmental conditions, with high percent mortality $100 \%$ followed by primiphos methyl, then chloropyrifos. Moreover, lambda- cyhalothrin was the most effective adulticide against all adult populations developed from larvae collected from different environment followed by deltamethrin and the lowest effective one was permethrin. On other hand, Cx. pipiens that were collected from Kafr El Sheikh showed the higher resistance to the most of tested insecticides, this may be due to extensive use of chemical insecticides.

To explain change in the response of mosquitoes to the used insecticides with difference in breeding habitats, a biochemical assay was conducted for two enzymes which are known to be implicated in insect resistance. The enzymes are acetylcholinesterase (AChE) and glutathione- S- transferase (GST). AChE is a common resistance mechanism observed in several species of arthropods [23]. Numerous studies have demonstrated that the increased metabolic detoxifications were involved in organophosphate resistance in many insect pests [24].

The results of biochemical analysis revealed elevation in the activity of both enzymes. The observed high levels of AChE and GST is supported the increase insecticide resistance in field populations of sewage water.

The present results agree with [25] who estimated that, number of organisms are known that tolerate acidic or alkaline conditions, but mosquitoes appear to be the most proficient $\mathrm{pH}$ regulators yet described. Aedes aegypti was unusual in their ability to survive and developed in waters ranging from $\mathrm{pH} \cdot 4$ to 11 . Also mosquitoes bred under different conditions showed considerable changes in mortality rates and body weight, with nutrition being the major factor, they also demonstrated that temperature, crowding and availability of nutrition during the larval stages directly or indirectly modulate 24 hours mortality in the adult 
when exposed to permethrin [26].

Salinity had a small but significant negative impact on the toxicity of Bacillus thuringiensis toxin to Aedes aegypti larvae. This had implications for the use of $B$. thuringiensis toxin as a larvicide in brackish waters [27, 28].

As mentioned, it has been shown before that any change during the larval stage life span influence the insecticide susceptibility of the adult mosquito [29].

\section{Conclusion}

It could be concluded that, the variation of the properties of breeding site characteristics had great effect on the susceptibility of $C x$. pipiens to different insecticides. The findings from this study strengthen the importance of environmental contributions and changes to the expression of resistance to insecticides in $C x$ pipiens mosquitoes. So we need to give environmental factors more attention especially in insecticide resistance assay manuals.

\section{References}

[1] Southgate, B. A. (1979): Bancroftian filariasis in Egypt. Tropical diseases bulletin, 76 (12): 1045-1068.

[2] Hanafi, H. A.; Fryauff, D. J.; Saad, M. D.; Soliman, A. K.; Mohareb, E. W.; Medhat, I.; Zayed, A. B.; Szumlas, D. E. and Earhart, K. C. (2011): Virus isolations and high population density implicate Culex antennatus (Becker) (Diptera: Culicidae) as a vector of Rift Valley fever virus during an outbreak in the Nile Delta of Egypt. Acta Trop., 119 (2): 119 124.

[3] Kabula, B. I.; Attah, P. K.; Wilson, M. D. and Boakye, D. A. (2011): Characterization of Anopheles gambiae sl and insecticide resistance profile relative to physiochemical properties of breeding habitats within Accra Metropolis, Ghana. Tanzania Journal of Health Research, 13 (3): 163-187.

[4] Garba, Y. and Olayemi, I. K. (2015): Spartial variation in physiochemical characteristics of wetland rice fields mosquito larval habitats in Minna, north Central Nigeria. In International conference on agricultural, ecological and Medical sciences. (pp. 11-4).

[5] Oyewole, I. O.; Momoh, O. O.; Anyasor, G. N.; Ogunnowo, A. A.; Ibidapo, C. A.; Oduola, O. A. and Awolola, T. S. (2009): Physiochemical characteristics of Anopheles breeding sites: Impact on fecundity and progeny development. African Journal of Environmental Science and Technology, 3 (12).

[6] Harbach RE. (1988): The mosquitoes of the subgenus Culex in southwestern Asia and Egypt (Diptera: Culicidae). Contrib. Amer. Ent. Inst., 24: 1-237.

[7] Chapman, H. C. and Barr, A. R. (1969): Techniques for successful colonization of many mosquito species. Mosquito, News, 29: 532-535.

[8] World Health Organization (2006): Pesticides and their applications, for the control of vectors and pests of public health importance. WHO/ CDS/ NTD/ WHOPES/ GCDPP/1.

[9] World Health Organization. (1981): Instructions for determining the susceptibility or resistance of mosquito larvae to insecticides. WHO/ VBC/ 81.807.

[10] World Health Organization (2005): Guidelines for laboratory and field testing of mosquito larvicides.

[11] World Health Organization. (1998): Test procedures for insecticide resistance monitoring in malaria vectors, bioefficacy and persistence of insecticides on treated surfaces: report of the WHO informal consultation, Geneva, 28-30 September 1998.

[12] Amin, T. R. (1998): Biochemical and physiological studies of some insect growth regulators on the cotton leafworm, Spodoptera littoralis (Boisd.) (Doctoral dissertation, Ph. D. thesis, Faculty of science, Cairo Univ).

[13] Bradford, M. M. (1976): A rapid and sensitive method for the quantitation of microgram quantities of protein utilizing the principle of protein-dye binding. Analytical biochemistry, 72 (1-2): 248-254.

[14] Simpson, D. R.; Bulland, D. L. and Linquist, D. A. (1964): A semimicro technique for estimation of cholinesterase activity in boll weevils. Entomological Society of American, 57: 367371.

[15] Habig, W. H.; Pabst, M. J. and Jakoby, W. B. (1974): Glutathione S-transferases the first enzymatic step in mercapturic acid formation. Journal of biological Chemistry, 249 (22), 7130-7139.

[16] Barrett, K. C.; Morgan, G. A.; Leech, N. L. and Gloeckner, G. W. (2012): IBM SPSS for introductory statistics: Use and interpretation. Routledge.

[17] World Health Organization (2013): Test procedures for insecticide resistance monitoring in malaria vector mosquitoes.

[18] Gould, E. A. and Higgs, S. (2009): Impact of climate change and other factors on emerging arbovirus diseases. Transactions of the Royal Society of Tropical Medicine and Hygiene, 103 (2), 109-121.

[19] Kipyab, P. C.; Khaemba, B. M.; Mwangangi, J. M. and Mbogo, C. M. (2015): The physiochemical and environmental factors affecting the distribution of Anopheles merus along the Kenyan coast. Parasites \& vectors, 8 (1): 221.

[20] Banerjee, S.; Mohan, S.; Saha, N.; Mohanty, S. P.; Saha, G. K. and Aditya, G. (2015): Pupal productivity \& nutrient reserves of Aedes mosquitoes breeding in sewage drains \& other habitats of Kolkata, India: implications for habitat expansion $\&$ vector management. The Indian journal of medical research, 142 (Suppl 1): S87.

[21] Juliano, S. A.; Lounibos, L. P. and O’Meara, G. F. (2004): A field test for competitive effects of Aedes albopictus on A. aegypti in South Florida: differences between sites of coexistence and exclusion? Oecologia, 139 (4): 583-593.

[22] Murrell, E. G. and Juliano, S. A. (2008): Detritus type alters the outcome of interspecific competition between Aedes aegypti and Aedes albopictus (Diptera: Culicidae). Journal of Medical Entomology, 45 (3): 375-383.

[23] Kady, G. A. E. L.; Kamel, N. H.; Mosleh, Y. Y. and Bahght, I. M. (2008): Comparative toxicity of two bio-insecticides (Spinotoram and Vertemic) compared with methomyl against Culex pipiens and Anopheles multicolor. World Journal of Agricultural Sciences, 4 (2): 198-205. 
[24] Yang, M. L.; Zhang, J. Z.; Zhu, K. Y.; Xuan, T.; Liu, X. J.; Guo, Y. P. and Ma, E. B. (2009): Mechanisms of organophosphate resistance in a field population of oriental migratory locust, Locusta migratoria manilensis (Meyen). Archives of Insect Biochemistry and Physiology: Published in Collaboration with the Entomological Society of America, 71 (1): 3-15.

[25] Clark, T. M.; Flis, B. J. and Remold, S. K. (2004): Differences in the effects of salinity on larval growth and developmental programs of a freshwater and a euryhaline mosquito species (Insecta: Diptera, Culicidae). Journal of Experimental Biology, 207 (13): 2289-2295.

[26] Owusu, H. F.; Chitnis, N. and Müller, P. (2017): Insecticide susceptibility of Anopheles mosquitoes changes in response to variations in the larval environment. Scientific reports, 7 (1): 3667.
[27] Jude, P. J.; Tharmasegaram, T.; Sivasubramaniyam, G.; Senthilnanthanan, M.; Kannathasan, S.; Raveendran, S. and Surendran, S. N. (2012): Salinity-tolerant larvae of mosquito vectors in the tropical coast of Jaffna, Sri Lanka and the effect of salinity on the toxicity of Bacillus thuringiensis to Aedes aegypti larvae. Parasites \& vectors, 5 (1): 269.

[28] Osborn, F. R.; Herrera, M. J.; Gómez, C. J. and Salazar, A. (2007): Comparison of two commercial formulations of Bacillus thuringiensis var. israelensis for the control of Anopheles aquasalis (Diptera: Culicidae) at three salt concentrations. Memórias do Instituto Oswaldo Cruz., 102 (1): 69-72.

[29] Kulma, K.; Saddler, A. and Koella, J. C. (2013): Effects of age and larval nutrition on phenotypic expression of insecticideresistance in Anopheles mosquitoes. PLoS One, 8 (3): e58322. 